\title{
Forecast of the Bidding Curve of Generation Players in the Iberian Electricity Market
}

\author{
Rúben A. Soares \\ INESC TEC \\ Campus da FEUP, \\ Rua Dr. Roberto Frias, 378 \\ 4200 - 465 Porto, Portugal \\ rasoares@inescporto.pt
}

\author{
João Tomé Saraiva, José Nuno Fidalgo \\ INESC TEC and FEUP/DEEC \\ Fac. Engenharia da Univ. do Porto \\ Rua Dr. Roberto Frias, 378 \\ 4200 - 465 Porto, Portugal \\ jsaraiva@fe.up.pt, jfidalgo@fe.up.pt
}

\author{
Berto C. Martins \\ EDP SA \\ Pr. Marques de Pombal, 12 \\ 1250 - 162 Lisboa, Portugal \\ berto.martins@edp.pt
}

\begin{abstract}
This paper reports the research that was developed to predict biding curves submitted by generation players to the Market Operator of the Iberian Electricity Market. In this scope, we used a data set based on publicly available information from the website of the Market Operator to develop a two-step ANN prediction model. The first step involves the prediction of the amount of energy bidden at zero price and the second ANN predicts the parameters of the equation of the line that better approximates the remaining bid curve. The tests were done using information of a large generation player but this approach can be replicated to other players so that the individual predicted curves can be composed in order to obtain the aggregated selling curve for each hour of the next day.
\end{abstract}

Index Terms-electricity markets, generation bid curves, neural networks, Iberian Electricity Market.

\section{INTRODUCTION}

The competitiveness in energy markets stimulates the search for advanced data treatment aiming at obtaining information advantages over competitors. In the Iberian Electricity Market, MIBEL, it becomes very important to understand the strategies of generation players to interpret market behaviour, namely the evolution of the market prices. On the other hand, each player aims at optimizing its positions, considering the revenues obtained from selling electricity at the highest market prices and the associated cost for generating and buying energy for their own customers.

Therefore, the ability to anticipate competitors' strategies is an important issue that can bring clear advantages to any market player. Accordingly, the objective of this paper is to describe a tool to forecast the bid curve for generation players in the MIBEL, taking into account historical publicly available data. This work was developed in the scope of the MSc thesis submitted by the first author FEUP in March 2014 and the topic was proposed by EDP Produção, one of the major generation players in the MIBEL [1].

During this research, it was recognized that the hourly selling bid curves submitted by several players include a segment at zero price, namely associated with wind generation, nuclear plants and also run of river stations, followed by set of bids having increasing prices. Therefore, two forecasting models were developed, both using Artificial Neural Networks (ANN). The first one was trained to predict the amount of energy bidden at zero price by a specific player for each hour of the day-ahead market. The second one forecasts the parameters of the equation of the line that better approximates the remaining bid curve. Both models were tested using MIBEL publicly available data for a specific player so that meaningful conclusions can be taken. The developed model can be replicated to other players so that ultimately the entire aggregated selling bid curve for each hour of the next day can be built and predicted.

According to previous ideas and objectives, this paper is organized as follows. After this Introduction, Section II briefly reviews the design of the MIBEL and describes the generation mix in Portugal and in Spain in order to understand the evolution of the market prices in recent years. Then, in Section III the two mentioned forecasting models are described as well as the application of ANN to this problem. Section IV includes details on the data set that was used and the main results, namely the forecasting errors that were obtained. The results obtained so far show a general good performance, supporting the feasibility of the proposed approach. Finally, Section V draws the most relevant conclusions and provides some indications regarding future developments.

\section{IBERIAN ELECTRICITY MARKET AND PRICE EVOLUTION}

\section{A. Evolution of the Portuguese power system}

The Portuguese power system was organized as a vertically integrated system since 1975. Then, in 1988 it was passed new legislation to induce investments in small hydro power plants (less than $10 \mathrm{MVA}$ ), cogeneration and other renewables sources. This legislation determined that these units were paid feed in tariffs that proved to be very successful given the current Portuguese generation mix. The Portuguese system started to be restructured in 1995 when a new set of laws were passed leading to the progressive 
unbundling of the system. In this scope, it was created an independent company to operate as TSO and a separate company to operate the distribution network and the larger hydro and thermal stations that started to be privatized in June 1997. Then, in 2001 it was signed a memorandum with Spain to create a common electricity market that should start in 2003. Several problems delayed this common market and meanwhile a new electricity law was passed in 2006. This law organized the system in four main activities - generation, transmission, distribution and retailing as well as in other technical, economic and regulatory activities. Regarding generation, it is subdivided in Normal Regime (bidding in the daily market or getting bilateral contracts) and Special Regime (corresponding to hydro stations smaller than 10 MVA, cogeneration units and units using renewable sources) that is paid by feed-in tariffs. Transmission and distribution are regulated activities and retailing is a competitive activity although a regulated last resource retailer still exists having the supply contracts with the end-users that didn't move to the free market. By the end of 2014, 3,400,000 out of $6,200,000$ clients are already in the free market with a share of $81 \%$ of the yearly demand.

By the end of 2013 the installed capacity corresponded to 18,117 MW, grouped as follows:

- Normal Regime -11,054 MW including 5,271 MW in hydro and 5,783 MW in thermal stations (coal stations $-1,752 \mathrm{MW}$, and combined cycles $-3,866 \mathrm{MW}$ );

- Special Regime -7,063 MW (1,466 MW of cogeneration units, $413 \mathrm{MW}$ in small hydro stations, 4,630 MW in wind parks, $282 \mathrm{MW}$ in PV stations and $267 \mathrm{MW}$ in thermal units using renewable sources).

In 2013 , the annual demand was $49,155 \mathrm{GWh}$ supplied by hydros, $27.1 \%$, coal stations, $22.3 \%$, combined cycles, $3.1 \%$, and renewable special regime generation, $44.9 \%$, namely wind parks with a share of $23.9 \%$, cogeneration with $14,5 \%$, biomass with $2.8 \%$ and photovoltaics with $0.9 \%$. Imports were $5.6 \%$ and the peak demand was close to 8,310 MW [2].

\section{B. Evolution of the Spanish power system}

The Spanish electricity market was launched in January 1, 1998 including a day ahead and intraday markets. The legislation recognizes four main activities: generation, transmission, distribution and retailing. Once again, normal regime generation bids in the market or gets bilateral contracts while special regime can choose receiving a feed-in tariff or biding in the daily market and receiving the market price plus a participation prize. Regarding the end of 2014 the total installed capacity was $102,260 \mathrm{MW}$ split as follows:

- Normal regime - 62,497 MW. This includes 17,756 MW of hydro stations, 7,866 MW in nuclear stations and 36,845 MW in conventional thermal stations (coal stations - 10,972 MW, fuel/ gas stations - 520 MW and combined cycles - 25,353 MW);

- Special regime - 39,763 MW. This includes 2,105 MW in small hydro stations, 22,845 MW in wind parks, 4,428 MW in PV units, $2300 \mathrm{MW}$ in solar units, 1,010 MW in other renewable thermal stations and 7,075 MW in other non-renewable stations.
Apart from the day-ahead market, the system also includes six sessions of the intraday market, typically used to trade small quantities of electricity or to adjust previously established buying or selling positions. System operation is under the responsibility of the Spanish TSO, Red Electrica de Espana, and full eligibility was achieved in 2003. In 2014 the annual generation was $260,242 \mathrm{GWh}$ with a peak power of $38,666 \mathrm{MW}$ in February 4th. This demand was supplied by hydro stations, $13.7 \%$, nuclear stations, $22.0 \%$, coal stations, $16.9 \%$, combined cycles, $8.4 \%$, and special regime generation, $39.0 \%$, with particular emphasis to wind generators with a share of $19.6 \%$.

\section{The Iberian Electricity Market}

In November 14th 2001 it was signed a memorandum between the Portuguese and the Spanish governments to create a common electricity market that afterwards evolved to a common energy market in the Iberian Peninsula also including gas. Negotiations between the two administrations, the two TSO's and the two regulatory agencies started soon afterwards and lead to the launch of a common longer term market in 2006 and to the common day ahead market in July 2007 as an extension of the already existing Spanish pool and intraday markets. Along these years the interconnection capacity between the two countries has been increased to values ranging from 2000 to $2500 \mathrm{MW}$ depending on the operation conditions of the two systems and there are plans to further increase it to $3000 \mathrm{MW}$ in the near future.

The common market includes a day-ahead market that accepts buying and selling bids to the next day 24 hour trading periods. These bids can be simple (in terms of pairs of prices and quantities) or complex (if generators include information regarding ramps or the minimum revenues obtained in a specific period). After an initial market based program is obtained by the Market Operator, the two TSO's validate the schedules together with bilateral contracts checking the limits of the interconnection lines. If these limits are violated, then a market splitting mechanism is used to solve the congestion leading to different prices in Portugal and in Spain. Then, each TSO checks the limits of internal branches in each country and solves eventual congestion using incremental /decremental bids submitted by generators. After obtaining a first feasible schedule, each TSO runs a market to assign up and down secondary reserve followed by specific markets to contract tertiary reserve. At 17:00 each day starts the first session of the intraday market that covers the next day and at 21:00 there is a second session also for the next day. Then, during the delivery day 4 other sessions of the intraday market run at 01:00, 4:00, 8:00 and 12:00. Most of the energy, above $85 \%$, is traded in the day-ahead market and in recent years the prices in the two countries converged as shown in Figures 1 and 2 because the interconnection capacity was enlarged, the generation mix in the two countries is more similar than in the past (apart from nuclear that only exists in Spain) and also because transmission networks are less congested. As a result, in 2008 congestion in the interconnection lines occurred in about $85 \%$ of the hours and this percentage declined to about $20 \%$ in 2013 and 2014. 


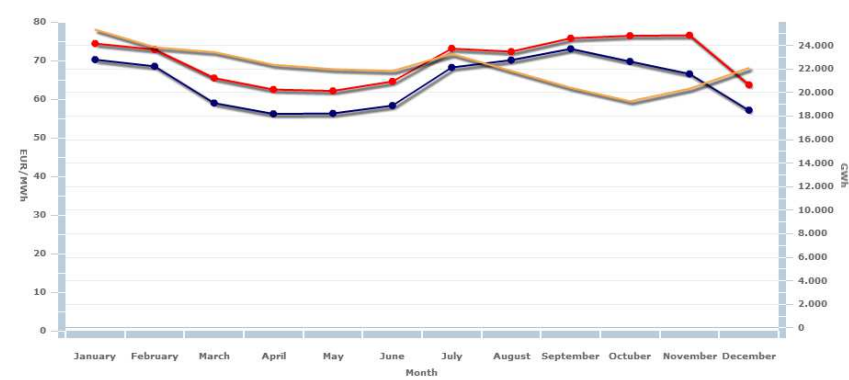

Figure 1 - Traded energy in the daily market (GWh) (orange) and average market prices ( $€ / M W h)$ in Portugal (red) and in Spain (dark) in 2008 [source

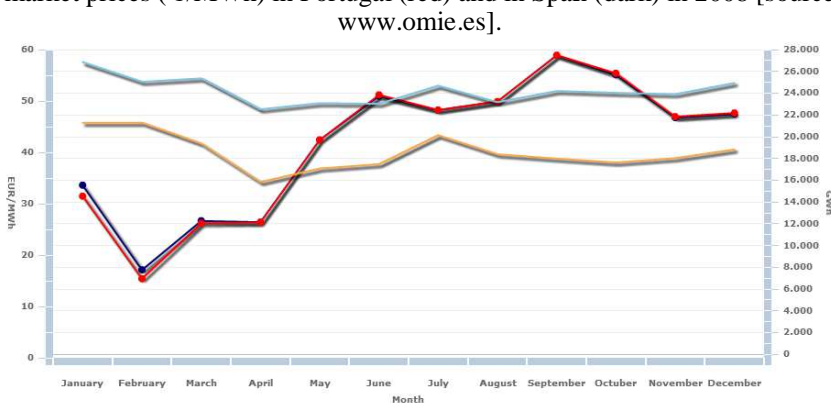

Figure 2. Traded energy (GWh) in the daily market (orange) and including bilateral contracts (light blue) and average market prices ( $€ / \mathrm{MWh})$ in Portugal (red) and in Spain (dark blue) in 2014 [source www.omie.es].

These graphs also show that average market prices have been declining. This is due to the demand reduction in 2012 and 2013 due to the economic crisis and also to the increasing share of subsidized generation. Estimates of the feed in generation are used to build the aggregated selling curve for each hour of the next day. Typically, these estimates are considered using zero price segments as this generation has dispatch priority. This originates the shift to the right of the selling curve of other traditional technologies and therefore a reduction of the market price. Figure 3 shows the aggregated buying and selling curves for hour 1 of March12, 2013 showing a long zero price segment of about 32,000 MWh associated to nuclear stations (7000 MWh), hydro stations (12,000 MWh) and Special Regime (about 13,000 MWh). It should also be noticed that as a result of this extended zero price segment, the market price at this hour was $0.0 € / \mathrm{MWh}$

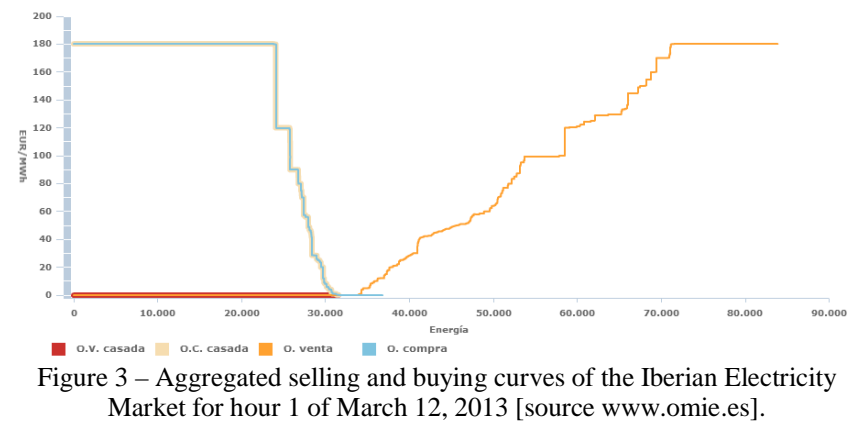

\section{Dominant production operators in MIBEL}

The operation of MIBEL is strongly determined by a set of generation players owning a larger share of capacity [3]. The current interconnection capacity between the two countries is still not enough to prevent market power and so the Portuguese and the Spanish Regulatory Agencies prepare on an annual basis a document identifying the MIBEL dominant players, considered as players having a market share exceeding $10 \%$ of the capacity in ordinary regime. Figure 4 details shares of the main generation players in Spain in 2012 as reported by the Spanish Regulatory Agency.

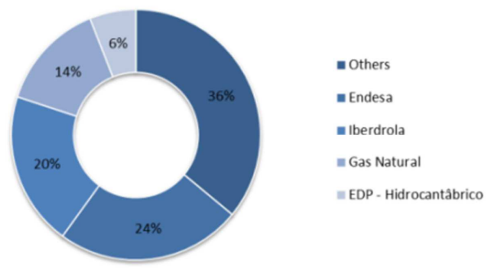

Figure 4. Shares of the main generation players in Spain in 2012 [4].

The forecasting models developed in this research were obtained considering data related with one of these players. These models can be replicated for the other generation players so that the entire selling curve for each hour of the next day can eventually be forecasted.

\section{PREDICTION OF GENERATION BID CURVES}

In order to forecast the bidding curve of a generation MIBEL player we developed two models, both of them using ANN [5], [6]. The first of them was built to forecast the amount of electricity bidden at zero price for a given hour of the next day (Model 1). The second model was established to forecast the equation that better approximates the bidding curve, apart from the amount bidden at zero price. In this case, we considered two alternatives, as detailed below:

- Model 2.a - line that approximates the bidding curve having a general equation of the form $\mathrm{y}=\mathrm{mx}$;

- Model 2.b - line that approximates the bidding curve having a general equation of the form $\mathrm{y}=\mathrm{mx}+\mathrm{b}$.

Figure 5 illustrates the forecasting models developed for a particular day, in this case for the hour 14 of February 21, 2013. As indicated in this Figure, the forecasting of the selling bid curve involves estimating the amount of electricity submitted to the Market Operator at zero price (estimated by Model 1) and the equation of the line that better approximates the remaining bidding curve (obtained by Model 2.a and 2.b).

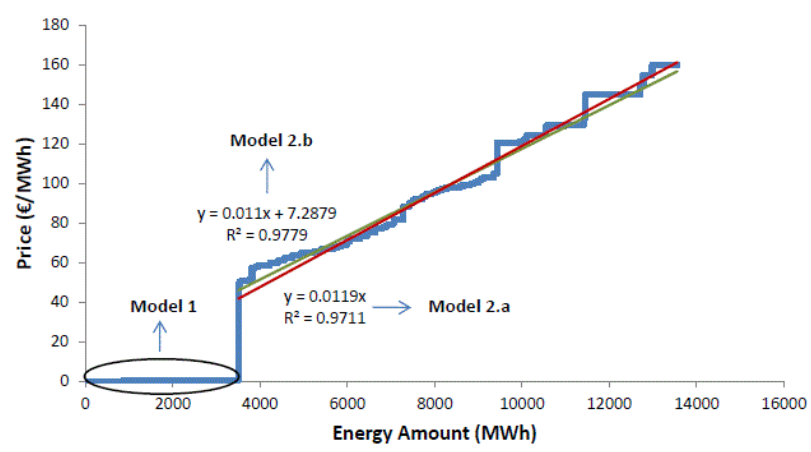

Figure 5. Aggregated selling curve submitted by a MIBEL generation player for the hour 14 of February 21, 2013, with the identification of the results of the three developed forecasting models (1, 2.a and 2.b). 
When developing the forecasting models, several sets of alternative input variables were tested to train the ANNs. Among the tested input data, we selected the sets that provided the best results taking into account the period under analysis. Table 1 details the input data used for each of the three developed ANN's, that is, for Model 1, Model 2.a and Model 2.b. Regarding these input variables, SP indicates that it was used data only from Spain, and SP-PT indicates that data both from Spain and Portugal was used.

TABLE I. Input variables used in the developed ANN's for Model 1, Model 2.a and Model 2.b.

\begin{tabular}{|l|c|}
\hline \multicolumn{1}{|c|}{ Variables } & Model \\
\hline Month & $1,2 . \mathrm{a}, 2 . \mathrm{b}$ \\
\hline Day of Week & $1,2 . \mathrm{a}, 2 . \mathrm{b}$ \\
\hline Hour & $1,2 . \mathrm{a}, 2 . \mathrm{b}$ \\
\hline Load Energy Forecast (SP-PT) & $1,2 . \mathrm{a}, 2 . \mathrm{b}$ \\
\hline Wind Energy Forecast (SP-PT) & $1,2 . \mathrm{a}, 2 . \mathrm{b}$ \\
\hline Daily Hydro Energy Balance (SP) & $2 . \mathrm{b}$ \\
\hline Hydro Reserves for a multiyear regime (SP) & $1,2 . \mathrm{a}$ \\
\hline MIBEL Daily Market Price & $1,2 . \mathrm{a}, 2 . \mathrm{b}$ \\
\hline Amount of Energy Offered at Zero Price by all players & $1,2 . \mathrm{b}$ \\
\hline Supply Player Curve & $2 . \mathrm{a}, 2 . \mathrm{b}$ \\
\hline Amount of Energy Bid at Zero price predicted with Model 1 & $2 . \mathrm{a}$ \\
\hline
\end{tabular}

Typically, nuclear plants bid zero price [www.omie.es] and hydros can also offer large amounts of energy at zero price if their reservoir levels are high. In some specific situations, they can also make price arbitrage to raise their profits. Besides, wind production is automatically accepted in the market. The combination of all these factors and their interaction with the other inputs (see Table I) is highly nonlinear, which justifies the application of ANN in this study.

The data used as input as well as the characteristics of the bid curves taken as output to train the ANN correspond to a series from January 6, 2013 to June 30 2013. This data was split in three subsets in the proportion of 3/1/1 ( 3 days in the training set, 1 in the validation set and another in the test set). The quality of the trained ANN was evaluated using the determination coefficient (R), the root mean squared error (RMSE) given by (1) and the mean absolute percentage error (MAPE) as indicated in (2). In these expressions $A_{i}$ is the real value taken by sample $\mathrm{i}, F_{i}$ is its estimated value and $n$ is the number of samples.

$$
\begin{gathered}
\mathrm{RMSE}=\sqrt{\frac{1}{n} \sum_{i=1}^{n}\left(A_{i}-F_{i}\right)^{2}} \\
\mathrm{MAPE}=\frac{1}{n} \sum_{i=1}^{n}\left|\frac{A_{i}-F_{i}}{A_{i}}\right| \cdot 100 \%
\end{gathered}
$$

\section{RESUlTS}

\section{A. Model 1}

In the first place, an ANN was trained to estimate the amount of energy bid a t zero price, Model 1, using the input variables indicated in Table I. The performance of the first ANN, ANN1, is indicated in Table 2 and Figure 6 shows the evolution of the MAPE associated to the prediction of the amount of energy bid at zero price for each hour of the day. This figure indicates that ANN1 has more difficulty in predicting the amount of energy bidden at zero price for the first 5 hours of the day, and particularly for the first 3 of these hours. For the hours after hour 5 the average value of the MAPE is $13.244 \%$. In order to have insight on the larger errors obtained for the initial 5 hours, we analyzed the reports made available by the MIBEL Market Operator regarding incidents affecting generation stations, namely planned and unplanned outages. This analysis showed that the hours having larger MAPE coincide with the outage of a large generation of this player or with the ramping down of thermal generation that also bids at lower prices. Therefore, we concluded that unplanned generation outages affect the bidding strategy of this player and so we admitted that the data regarding the initial hours of the day when a station had an unplanned outage correspond to outliers of the database. Accordingly, this data were eliminated from the database and a new ANN, ANN2 was trained to predict the amount of energy bidden at zero price. The performance of ANN2 is also given in Table II and Figure 6 shows the evolution of the MAPE for the different hours of the day. When comparing the results obtained with these two ANN's, ANN2 provides a reduction of the MAPE in the first two hours, while maintain the average value for the remaining ones.

\begin{tabular}{|c|c|c|c|c|c|}
\hline Model & $\begin{array}{c}\text { MAPE } \\
\text { Total } \\
(\%)\end{array}$ & $\begin{array}{c}\text { MAPE } \\
\text { Test } \\
(\%)\end{array}$ & $\begin{array}{c}\text { RMSE } \\
\text { Total } \\
\text { (MWh) }\end{array}$ & $\begin{array}{c}\text { RMSE } \\
\text { Test } \\
\text { (MWh) }\end{array}$ & $\begin{array}{c}\text { R } \\
\text { Test }\end{array}$ \\
\hline $1-$ ANN1 & 17.471 & 20.121 & 776.98 & 961.15 & 0.902 \\
\hline 1 - ANN2 & 15.409 & 18.900 & 737.90 & 940.48 & 0.904 \\
\hline
\end{tabular}

TABLE II. Performance of the developed ANN's for Model 1.

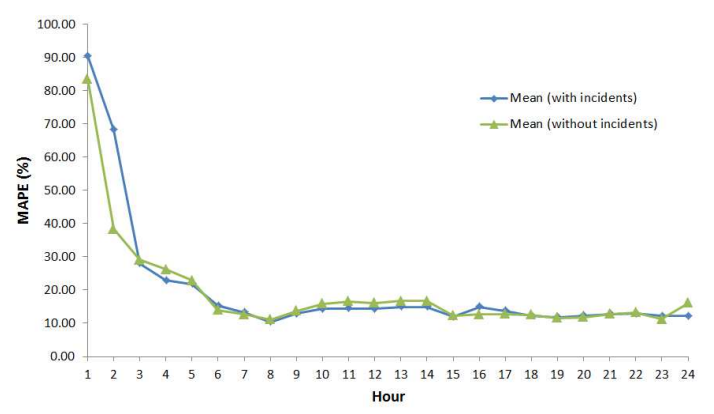

Figure 6. Average value of the MAPE for each hour of the day obtained using ANN1 and ANN2 for Model 1.

\section{B. Model 2}

In order to implement Model 2 we tested the use of linear equations of the form $\mathrm{y}=\mathrm{mx}$ and $\mathrm{y}=\mathrm{mx}+\mathrm{b}$ corresponding to Model 2.a and 2.b. Model 2.a involves the prediction of the slope of the line, $\mathrm{m}$, while for Model 2.b both the slope, $\mathrm{m}$, and the intersection with the vertical axis, $b$, are predicted. The results obtained with the predictions of these variables are given in Table III.

TABLE III. Performance of the developed ANN's used to estimate the

\begin{tabular}{|c|c|c|c|c|c|}
\hline \multirow[b]{2}{*}{ Model } & \multicolumn{2}{|c|}{$\mathbf{m}$} & \multicolumn{2}{|c|}{ b } & \multirow[b]{2}{*}{$\begin{array}{c}\mathbf{R} \\
\text { Test }\end{array}$} \\
\hline & $\begin{array}{c}\text { MAPE } \\
\text { Total } \\
(\%)\end{array}$ & $\begin{array}{c}\text { MAPE } \\
\text { Test } \\
(\%)\end{array}$ & $\begin{array}{c}\text { MAPE } \\
\text { Total } \\
(\%)\end{array}$ & $\begin{array}{c}\text { MAPE } \\
\text { Test } \\
(\%)\end{array}$ & \\
\hline $2 . \mathrm{a}$ & 6.552 & 8.186 & - & - & 0.902 \\
\hline 2.b & 6.842 & 8.589 & 4.711 & 5.175 & 0.930 \\
\hline
\end{tabular}
equations of the lines associated with Model 2.a and Model 2.b. 
The results in this table show that the prediction of the slope $\mathrm{m}$ for Model 2.a is better than for Model 2.b namely taking into account the MAPE values for the test set. Therefore, Model 2.a should be preferred and used whenever possible not only because of the better quality of the prediction of $\mathrm{m}$ but also because it is not necessary to predict any other variable (coefficient b in Model 2.b) that would increase the total error of the estimates.

\section{Final Prediction Model}

The development of the final prediction model implied the analysis of the hourly biding curves of this generation player. This evaluation showed that the selling curves submitted by this player to the Market Operator typically have a larger slope when the biding energy exceeds $30 \%$ of the installed capacity of this player. Therefore, the final prediction model was implemented as follows:

- in the first place it is predicted the amount of energy bidden at zero price using Model 1;

- then, if this amount exceeds $30 \%$ of the installed capacity of this player, Model 2.b is used to better approximate the biding selling curve;

- if this $30 \%$ bidden at zero price energy threshold is not reached, then Model 2.a is enough to ensure an adequate approximation to biding curve of this player.

Figures 7 and 8 illustrate the application of this procedure for hours 20 of May 5, 2013 and 18 of April 20, 2013.

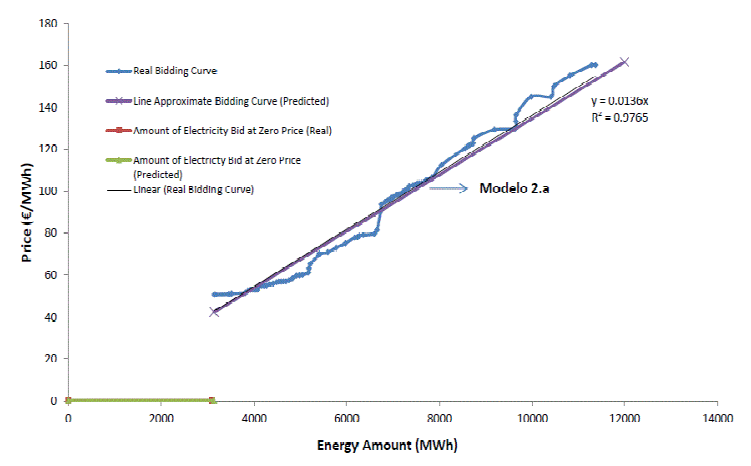

Figure 7. Final predictions for hour 20 of May 5, 2013.

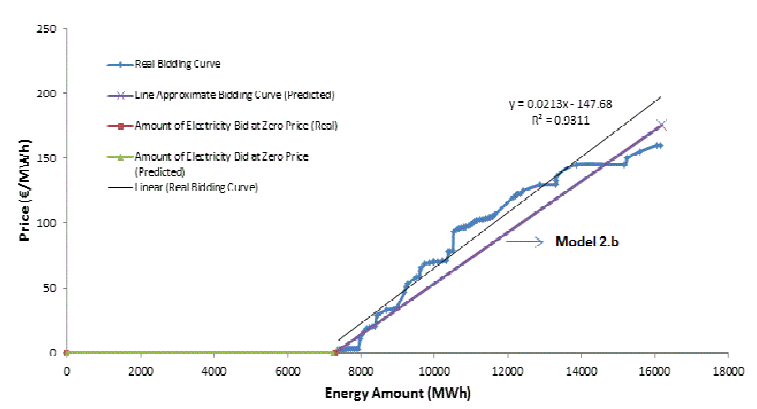

Figure 8. Final predictions for hour 18 of April 20, 2013.

\section{CONCLUSIONS}

The prediction of the strategies of market players is an important issue in the scope of the Iberian Electricity Market.
In general, when developing tools to forecast bidding strategies it is important to recognize that these bids are prepared by market analysts and therefore this involves a human component that can bring some degree of uncertainty to the definition of the bidding curves. In this scope, issues as risk aversion or profit willingness can have an impact on these strategies. Apart from these difficulties, the developed research showed that it is more difficult to predict the amount of energy bidden at zero price (as showed by the results obtained using Model 1) namely for the first 3 to 5 hours of each day. On the other hand, unplanned outages of generation units also have a relevant impact on the biding strategy of the analyzed market player. This suggests that the prediction results should be adjusted whenever these outages occur.

The analysis of the selling curves submitted by this market player to the Market Operator also suggested that the slope of the curve increases if the amount of energy bidden at zero price exceeds $30 \%$ of the installed capacity. Accordingly, Model 2.a or 2.b should be used in face of the results provided in the first place by Model 1 .

Finally, it is clear that this work was developed using data publicly available for one particular generation player in the Iberian Electricity Market. However, the described reasoning can be replicated for other players provided that the parameters of the prediction models are adjusted, or in other words, the weights of the corresponding ANN's are retrained. At the end, and if these prediction models are available for all generation players, then the individual prediction curves can be aggregated so that the entire selling curve for each hour of the next day is estimated.

\section{ACKNOWLEDGMENT}

This work was developed in the scope of the preparation of the MSc Thesis of the first author that is thankful to EDP SA, namely to Eng. Berto Martins for the discussions and suggestions that were provided.

\section{REFERENCES}

[1] R.Soares, "Analysis of the behavior of the generation agents of MIBEL" (in Portuguese), MSc Dissertation, Faculdade de Engenharia da Universidade do Porto, February 2014. [online]. Available: http://repositorio-aberto.up.pt/bitstream/10216/71520/2/52410.pdf

[2] OMIE, "Decision of May 9th 2014 that approves the Operation Rules of the day ahead and intraday Markets of generation of electricity of MIBEL". [online]. Available: www.omie.es/inicio/normativa-demercado/reglas-omie

[3] Conselho de Reguladores do MIBEL, "Operador Dominante Metodologia e Aplicações". [online]. Available: http://www.cmvm.pt/CMVM/Cooperacao\%20Internacional/Conselho\% 20Reguladores\%20Mibel/Documents/0ba5a612265c440d9a40efe9b720 2789PropostasobreOperador_dominante1.pdf.

[4] Comisión Nacional de Energía, "Spanish Energy Regulator's National Report To The European Commission 2013”, 24 July 2013. [online]. Available:http://www.cnmc.es/Portals/0/Ficheros/Energia/Publicaciones Anuales/Anuales_inf_europeo_2013.pdf

[5] Hsiao-Tien Pao, "Forecasting electricity market pricing using artificial neural networks", Energy Conversion and Management, Vol. 48, Issue 3, March 2007, pp. 907-912.

[6] G. Zhang, B. Eddy Patuwo, M. Y. Hu, "Forecasting with artificial neural networks: The state of the art", International Journal of Forecasting, Volume 14, Issue 1, 1 March 1998, pp. 35-62. 